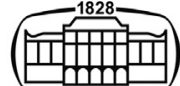

AKADÉMIAI KIADÓ

Evolution, Mind and

Behaviour

$18(2020) 1,1-13$

DOI:

$10.1556 / 2050.2018 .00008$

(c) 2020 The Author(s)

ORIGINAL RESEARCH PAPER

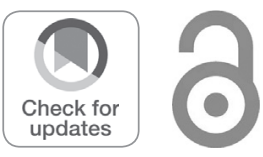

\section{Environmental stress effects on appetite: Changing desire for high- and low-energy foods depends on the nature of the perceived threat}

\author{
JIM B. SWAFFIELD* (- and QI GUO
}

University of Alberta, Edmonton, AB, Canada

Received: June 23, 2018 • Accepted: June 3, 2020

Published online: July 28, 2020

\begin{abstract}
It is well-documented that harsh environmental conditions influence appetite and food choice. However, the experience of environmental harshness is complex and shaped by several underlying dimensions, notably threats to one's social support, economic prospects, and physical safety. Here, we examined the differential effects of these three dimensions of environmental harshness on desire for specific food items. We first showed 564 participants images of 30 food items. Next, they rated how much they desired each item. The participants were then randomly assigned to a condition where they read one of six scenario stories that described someone's current living conditions. Each scenario story emphasized one of the three dimensions (social support, economic prospects, physical safety), with two levels (safe, harsh). Following this, the participants once again rated how desirable each food item was. The results showed that exposure to cues of low social support and high physical threat reduce the desire to eat, whereas cues of economic harshness had little effect. Further analysis revealed a significant interaction between energy level of different foods and perceived threat to physical safety. These findings are important in helping to understand how current environmental conditions influence changes in appetite and desire for different kinds of food items.
\end{abstract}

\section{KEYWORDS}

life history, food scarcity, stress, environmental harshness, appetite, evolution

\section{INTRODUCTION}

Harsh environmental conditions create fast life history ecologies (Kruger \& Kruger, 2016; Mittal \& Griskevicius, 2014) and are often associated with food scarcity, nutritionally poor food resources and high competition for available food supplies (Hill, Rodeheffer, Delpriore, \& Butterfield, 2013). Wells (2010) also states that throughout history food scarcity has been more common than food excess and those who were sensitive to cues associated with harsh conditions would be more likely to act in an adaptive manner that would aid in survival.

Harsh environments are often stressful. How stress effects appetite is dependent upon the intensity of the stressor. Acute or high intensity stress tends to decrease appetite (Sinha \& Jastreboff, 2013; Torres \& Nowson, 2007). Harsh environments may include dangers and threats to one's survival. Therefore, a decrease in appetite in high stress environments may be adaptive because it enables the individual to stay focused on threat reduction rather than food acquisition (Dagher, 2009).

In contrast, mild stress tends to increase appetite (Born et al., 2009). It is postulated that the desire to consume energy dense foods when an individual experiences mild stress is also an adaptive response that aids survival. For example, short-term stress may result from threats in the environment that have the potential to cause physical harm; these threats and the associated stress response help to prepare the body for a fight or flight response (Sapolsky, 2004). Under conditions of mild stress, the body prepares for this response by increasing the desire to eat which in turn provides fuel for the muscles (Sapolsky, 2004). In the longer term, 
chronic stress may also influence eating behavior. One example of a chronic stressor is the perceived likelihood of a future food shortage. It is hypothesized that, as environmental conditions become harsher, a sense of food resource scarcity is triggered (Nettle, Andrews, \& Bateson, 2016; Nettle et al., 2019). According to the Insurance Hypothesis, in an environment where food resources vary in supply, the drive to over-consume is adaptive because it enables the development of excess fat stores that might buffer the impact of a future famine (Nettle et al., 2016). In support of this idea, Hill, Griskevicius, Prokosch, and Kramer (2016) have demonstrated that harsh environments experienced during childhood can have long-term prospective effects, calibrating the body to prefer high-energy dense foods later in adulthood. Such adaptive responses can also occur rapidly in response to changes in perceived environmental conditions. For example, Laran and Selarno (2013) and Swaffield and Roberts (2015) have shown experimentally that even simple and transient manipulations of the perception of environmental harshness can trigger an immediate desire for food consumption, particularly for high-energy dense foods.

While it is well-established that the perception of environmental harshness can influence eating behavior, harshness is a multi-dimensional concept and includes a number of different conditions that contribute to a state of being stressed. A harsh environment may include having a poor social support network (Mccullough, Pedersen, Schroder, Tabak, \& Carver, 2013), poor economic conditions needed to acquire the necessities of life (Mcgregor \& Pouw, 2016) and perhaps also threats to one's emotional and physical safety (Gunstad et al., 2006; O'Shaughnessy \& Dollos, 2009). To better understand how the perception of current and possible future environmental conditions influences food consumption, these variables need to be isolated and analyzed individually. Hence, the focus of this study is to examine the effect of different types (social support, economic prospects, physical safety) and levels of harshness (safe, harsh) on food preference.

\section{The impact of the social environment on food consumption}

A safe social environment is one where an individual feels emotionally connected and valued by their family and peers. Safe social environments promote food sharing (Kaplan, Hill, Lancaster, \& Hurtado, 2000), which in turn can promote survival by establishing supportive friendships, cement social bonds and promote prosocial behavior (Crittenden \& Zes, 2015). As humans have an apparently innate need to be socially connected (Baumeister \& Leary, 1995) it is logical to assume that food sharing can have a positive effect on an individual's physical and emotional well-being.

Enloe (2003) also found that the Inuit of Akulivik increase food sharing behavior during periods of food scarcity. Enloe (2003) proposes that the practice of food sharing may be an adaptive risk reduction strategy in harsh environmental conditions. Specifically, the act of sharing creates an expectation of reciprocity whereby the one who shares food today may count on receiving food in return when they have insufficient food resources.

It has also been found that people from safe social environments make healthier food choices and eat less than those who come from harsh social environments (MacFarlane, Crawford, Ball, Savige, \& Worsely, 2007; Pott, Albayrak, Hebebrand, \& Pauli-Pott, 2009). Bauer, Hearst, Escoto, Berge, and Neumark-Sztainer (2012) also state that supportive families are more likely to have meals together. Eating together as a family provides an opportunity for members to connect with one another emotionally and enables parents to teach and reinforce healthy eating habits (MacFarlane, Crawford, Ball, Savige, \& Worsely, 2007).

Parents who are unresponsive to their children's emotional and physical needs, and who are verbally abusive and excessively controlling also contribute to harsh environmental conditions which can lead to elevated stress, excessive weight gain and obesity (Gunstad et al., 2006; O'Shaughnessy \& Dollos, 2009). Individuals from these nonnurturing environments often state they feel insecure, isolated, rejected and lonely (Troisi \& Gabriel, 2011). This lack of social support can lead to emotional eating and the consumption of energy dense comfort foods to make one feel better (Stojek, Fischer, \& MacKillop, 2015). If these harsh social conditions are chronic, they can lead to disordered eating behavior (Latzer, Hochdorf, Bachar, \& Canetti, 2002; Sinha \& Jastreboff, 2013; Tate, Spruit-Metz, Pickering, \& Pentz, 2015; Ty \& Francis, 2013).

\section{The impact of economic status on food consumption}

Prior research has shown that there is a strong negative association between both income and obesity (Borders, Rohrer, \& Cardarelli, 2006; Garawi, Devries, Thorogood, \& Uauy, 2014; McLaren, 2007; Shaw, Green, Popham, \& Benzeval, 2014) and between low income and preference for high-energy dense foods (Dressler \& Smith, 2013). However, it is difficult to conclude that low income alone is the driver of excess food consumption because income is related to other psychosocial factors such as level of education (United States Department of Labor, 2018) and stress levels (Macleod, Smith, Metcalfe, \& Hart, 2005). Others have suggested the reason low income individuals often have a higher body mass index (BMI) is because high-energy food is often less expensive than low-energy foods (Drewnowski \& Specter, 2004). The price of food argument has some limitations as it does not explain why low-income women are more likely to be obese than low income men (World Health Organization, 2018). Nor does it explain why lowincome individuals often eat more than their daily caloric needs.

\section{The impact of perceived physical safety on food consumption}

Individuals who live in harsh environments are often physically abused or live in fear of being abused. Abuse can come in a variety of forms including physical, sexual, as well as being harassed, threatened or bullied. A less obvious form 
of abuse is benign neglect that creates a feeling of insecurity and being unprotected from physical dangers (Williamson, Thompson, Anda, Dietz, \& Feiitti, 2002). Physically harsh environments are highly correlated with both childhood and adolescent obesity (Gunstad et al., 2006; O'Shaughnessy \& Dollos, 2009) as well as adult obesity (Alvarez, Pavao, Baumrind, \& Kimerling, 2007; Williamson et al., 2002). It has also been reported that childhood sexual and physical abuse doubles one's likelihood of being overweight or obese as an adult (Rohde et al., 2008).

Food scarcity is also associated with physically harsh environments and kleptoparasitic behavior (Hadjichrysanthou \& Broom, 2012; Stevens, 2004). Kleptoparasitic behavior involves stealing food that was acquired by other humans and animals and is most likely to occur under conditions of famine (Schoe, Iognh, \& Croes, 2009). The act of stealing another's food can lead to violent altercations as the defender tries to protect their food resources. Primate studies have shown that food sharing can be an adaptive behavior that reduces violent altercations and therefore, reduces the chance of incurring a life-threatening injury (Hadjichrysanthou \& Broom, 2012; Stevens, 2004).

\section{The impact of epigenetics on food consumption}

The literature to this point has discussed the impact of environmental conditions on appetite and food preference. There is also a developing body of research that examines the influence of genetic and epigenetic factors on eating behavior. Epigenetic studies have shown that harsh environmental triggers can affect the development of psychiatric disorders, metabolic disorders such as type 2 diabetes and insulin resistance (Iman \& Ismail, 2017; Li \& Lumey, 2019; Meng et al., 2018). In addition, appetite, satiety responsiveness, and the drive to eat in the absence of hunger are also related to epigenetic effects (Gardner, Sapienza, \& Fisher, 2015; Iman \& Ismail, 2017).

Some harsh environmental conditions such as famine, if experienced prenatally can alter gene expression and subsequent eating behavior. Famine and nutrient deficiencies can also have a transgenerational effect and influence gene expression and appetite of future generations (Cunliffe, 2016; Gardner et al., 2015; Heijmans et al., 2008; Iman \& Ismail, 2017). Robertson, Coall, Mcaullay, and Nannup (2019) succinctly summarize this point by stating that in some situations some people are born epigenetically primed for a hungry life.

Other researchers have found that conditions such as famine, if experienced prenatally and during early childhood can lead to different outcomes for men and women. In a 2018 study, researchers from Anhui Medical University in China performed a meta-analysis on 20 studies that examined the effect of prenatal and childhood famine on adult BMI. The famine studies included in this analysis occurred in Asia, Europe and Africa between the years of 1940 and 1980. This analysis concluded that famine exposure prenatally and during early life may increase BMI. They also found that the impact of a famine exposure impacts females more than males (Zhou et al., 2018).

In brief, the epigenetic and transgenerational impact of environmental conditions experienced prenatally and during early childhood could impact food preference, the volume of food desired and BMI throughout the lifespan.

\section{The current study}

As we have briefly reviewed, there are established links between different environmental conditions and eating behavior. Here, to develop a deeper understanding of how environmental harshness influences food desire, we explicitly examine and compare the effects of three core dimensions of environmental harshness (social, economic, physical safety). We build on earlier work (Swaffield \& Roberts, 2015) that showed when humans are exposed to harsh environment primes they experience an increased desire to consume high-energy dense food. In that study, participants were randomly assigned to either a "safe" or "harsh" environment condition. In one condition the participants read a 1 paragraph scenario story about a young woman in her early 20 s, who was living in a "safe" environment. In the second condition the same young woman was living in a "harsh" environment. A limitation of this study was that the environmental scenario stories interwove social, economic and physical safety elements. As a result, it is unknown whether all three dimensions played an influential role in triggering the increased desire for energy dense food, or if one dimension was more important than the others. In addition, the three dimensions may not be wholly independent: for example, good economic conditions enable the acquisition of resources that promote physically safe environmental conditions, and both may enable the development of supportive social networks. To address these issues, we developed a new set of scenario stories that isolated the social, economic and physical safety dimensions and, varied them so that there was a "safe" and "harsh" version of each. This allowed us to parse the effects of different dimensions of environmental harshness on an individual's desire to eat and food type preference. The scenario stories were written by the authors with consideration to three criteria. First, the scenario had to capture the essence of the different types of environmental conditions. Second, they had to be exclusive, that is, there was to be no overlap between scenarios. Third, the stories needed to be similar in length.

\section{METHODS}

\section{Participants}

For this experiment a total of 859 participants from the United States were recruited through the Amazon Mechanical Turk (M-Turk) crowd sourcing service. Each participant was paid a nominal fee $(\sim \$ 1.25)$ to participate. We calculated that the average length of time to complete this experiment should be between 12 and $13 \mathrm{~min}$. 
Table 1. Mean age and sex of participants in each scenario

\begin{tabular}{|c|c|c|c|c|c|c|}
\hline \multirow[b]{2}{*}{ Scenario } & \multicolumn{3}{|c|}{ Male } & \multicolumn{3}{|c|}{ Female } \\
\hline & Mean age & Standard deviation & Number & Mean age & Standard deviation & Number \\
\hline Safe Social & 36 & 13 & 47 & 39 & 13 & 44 \\
\hline Harsh Social & 36 & 10 & 42 & 40 & 13 & 48 \\
\hline Safe Economic & 38 & 13 & 54 & 39 & 12 & 49 \\
\hline Harsh Economic & 35 & 11 & 48 & 37 & 12 & 46 \\
\hline Safe Physical & 34 & 10 & 49 & 41 & 13 & 42 \\
\hline Harsh Physical & 36 & 10 & 46 & 37 & 11 & 49 \\
\hline
\end{tabular}

Therefore, before the analysis, we inspected the distribution of response times and excluded any participants whose response time indicated they had paid insufficient attention to the task $(<5.5 \mathrm{~min})$. Participants were asked if they suffered from any form of food allergy, were vegetarian/vegan, or had religious beliefs that influenced their food choices. If a participant stated "yes" to any of these questions, their responses were also excluded from analyses. This left 564 participants in the final analysis (mean age $37.2, \mathrm{SD}=11.73$ ), of whom $278(49.3 \%)$ were women and 286 (50.7\%) were men (Table 1).

\section{Procedure}

Having provided informed consent, the participants were given a URL to the online experiment. They were then shown images of 30 food items, as displayed in Fig. 1. These images constituted five items from each of the major food categories (vegetables, fruits, grains, dairy, meat/poultry, and sweets); original images are available from the authors on request. Images were presented in a different randomized order for each participant. Participants viewed each image and rated it according to the following question which was displayed below the image: "How desirable is this food item to you right now?" Ratings were recorded using a 7-point scale (anchored with the descriptors $1=$ extremely undesirable and $7=$ extremely desirable).

After the 30 food items had been rated for preference, participants were randomly assigned to one of six conditions; safe/harsh social support, safe/harsh economic prospects, or safe/harsh physical safety. They were asked to read an accompanying scenario text (see Appendix 1). Each scenario text depicted environmental conditions associated with the condition group to which they were assigned. The scenario text concluded with the sentence, "Pause for a moment and think about the story you just read. How would you feel if this really was your situation?"

Once the scenario had been read, the participants were asked to rate the same 30 food items for a second time. The food images were presented in a new and fully randomized order. Finally, participants were asked to identify their sex and age.

\section{Analysis}

We performed three main analyses. First, we conducted a two-way ANOVA to examine the effect of scenario (i.e., social, economic and physical) and level of harshness (i.e., safe versus harsh conditions) on changes in overall food desirability, using computed mean scores across all food

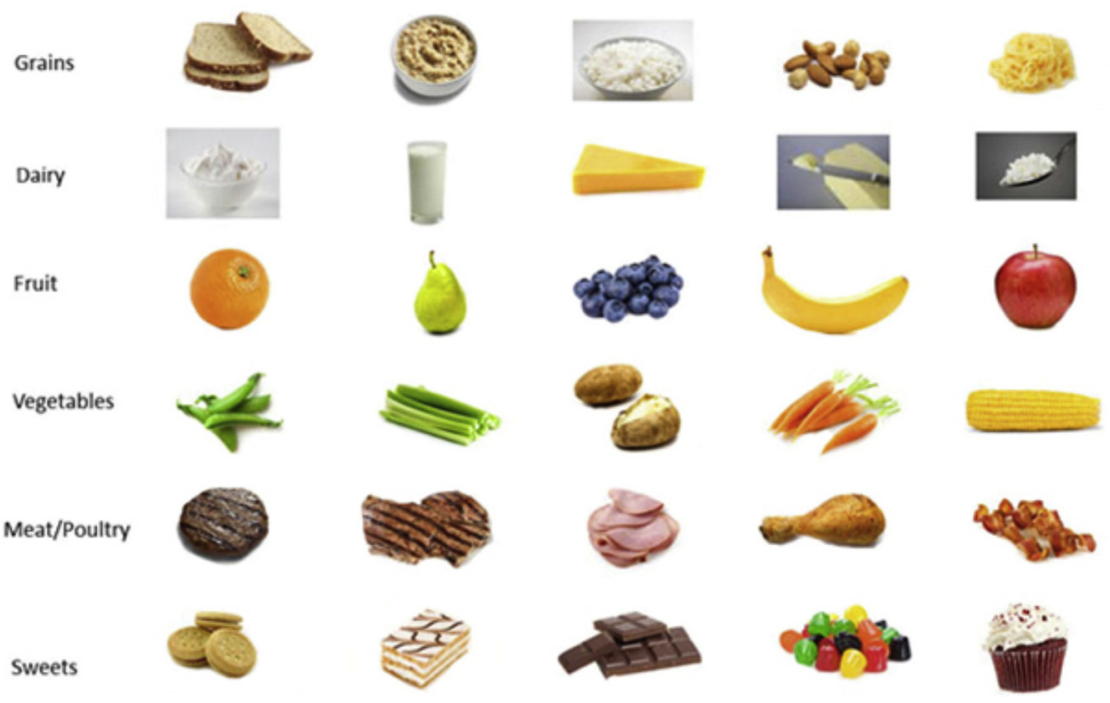

Fig. 1. Food images used in experiment 
items. We did not include sex as a between-subjects factor because preliminary analysis revealed no significant main sex effect, nor any significant interactions, on change in food desirability scores. Next, we used repeated-measures ANOVA to look at the effect of food energy density (low and high calorific value) and environmental harshness on food preference for each scenario separately. The calorific value of each food item was determined based on the dataset of the British Nutrition Foundation (2009) (http://www.nutrition. org.uk/healthyliving). Food items were split into two equally sized groups (Energy Value, 15 "high-energy" foodstuffs, and 15 "low-energy" foodstuffs) based on their calorific value. High-energy foods included ham, spaghetti, chicken, steak, bread, hamburger, cupcake, candy, cheese, pastry, cookies, chocolate, bacon, nuts and butter; low-energy foods were celery, carrots, pear, milk, orange, apple, blueberries, yogurt, oatmeal, potato, peas, corn, banana, cottage cheese and rice. For full details of calorific values see Swaffield and Roberts (2015). Finally, we conducted a further repeated-measures ANOVA to investigate the differential effects of the scenarios on desire among different major food categories represented in the image set (vegetables, fruits, grains, dairy, sweets and meats). For all analyses, partial eta squared were reported as a measure of effect size. Based on Bakeman (2005), a partial eta squared of 0.01 is considered small, a partial eta squared of 0.06 is considered medium, and a partial eta squared of 0.14 is considered large.

\section{RESULTS}

\section{Descriptive statistics}

The descriptive statistics for all dependent variables are reported in Table 2. Kolmogorov-Smirnov and Shapiro-Wilk tests were used to test the normality assumption. Significant violation of normality assumption was observed for all variables. However, simulation studies have shown that general linear model (e.g., ANOVA, repeated measure) are quite robust to violation of normality, especially when sample size is greater than 30 (Blanca, Alarcon, Arnau, Bono, \& Bendayan, 2017).

\section{Changes in general food desirability}

We first used a two-way ANOVA to examine the betweensubject effects of scenario (i.e., social, economic and physical safety) and harshness (i.e., safe versus harsh conditions) on changes in general food desirability (i.e. mean desirability change for all foods combined). This analysis (Fig. 2) revealed a significant main effect of scenario on food preference $F(2,558)=7.93, P<0.001$, partial eta squared $=0.028$. There was a slight increase in food desirability scores in those participants who read the economic scenarios (mean change $=0.003)$ but, in contrast, participants who read the social $(-0.165)$ and physical safety scenarios $(-0.236)$ experienced decreases in food desirability. Post-hoc Least Significant Difference (LSD) tests indicated that changes in desirability scores in the social $(P=0.007)$ and physical 


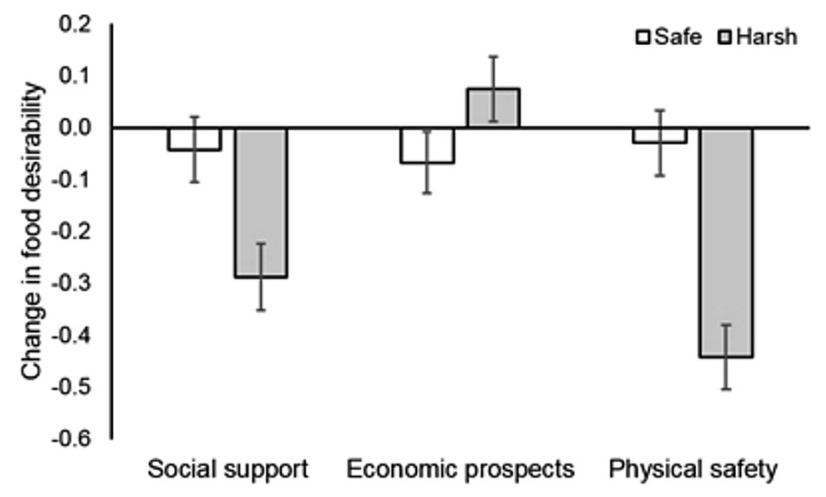

Fig. 2. Difference in mean pre-test and mean post-test desirability scores across all food items

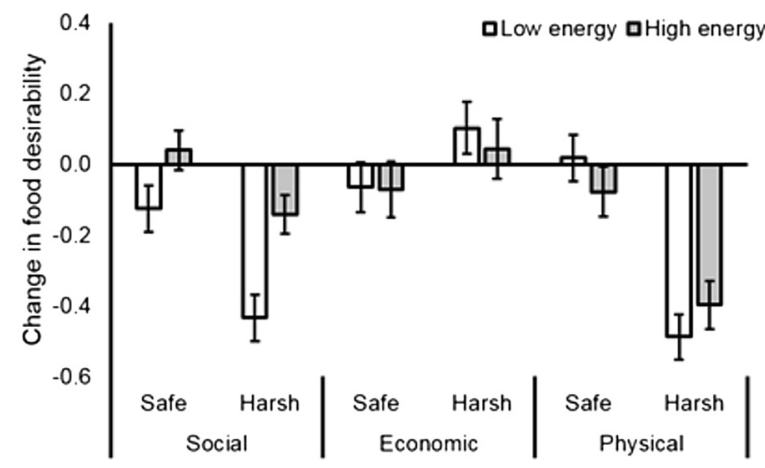

Fig. 3. Difference in mean pre-test and mean post-test food desirability scores by energy density level

safety $(P<0.001)$ scenarios were significantly different from the economic scenario, but not different from each other. There was also a main effect of level of harshness on food preference $F(1,558)=11.45, P=0.001$, partial eta squared $=0.020$, with a much larger decrease in food desirability in participants exposed to the harsh scenarios (mean change $=$ $-0.219)$ compared to those exposed to the safe scenarios $(-0.047)$.

More importantly, however, there was also a significant interaction effect between scenario and level of harshness, $F(2,558)=10.62, P<0.001$, partial eta squared $=0.037$. As shown in Fig. 3, participants exposed to the safe conditions experienced minimal change in food desirability across all three scenarios (social -0.042 , economic -0.068 , physical safety -0.030). In contrast, in the harsh conditions, participants experienced minimal change in the economic scenario (0.074), but food desirability scores were significantly reduced in the social $(-0.288 ; P<0.001)$ and especially the physical safety $(-0.443 ; P<0.001)$ scenarios.

\section{Effects of calorific value}

Next, we examined whether the effect of environmental condition (safe, harsh) in each scenario (social, economic, physical) affected changes in food desirability differently depending on food energy density level (low and high calorific value). We therefore conducted a repeated-measures ANOVA with energy level as the within-subject factor and harshness as between-group factor, for each scenario separately. In this analysis, an energy level $\times$ harshness interaction effect would indicate that changes in food desirability scores following exposure to the scenario would be influenced by calorific value. This analysis (see Fig. 3) revealed that, while the interaction effects were not significant in either the social $(F(1,179)=2.01, P=0.158$, partial eta squared $=0.011)$ or economic $(F(1,195)=0.33$, $P=0.564$, partial eta squared $=0.002$ ) scenarios, the energy level $\times$ harshness interaction was significant in the physical scenario $(F(1,184)=6.69, P=0.010$, partial eta squared $=0.035)$. Here, the overall decrease in desirability was less marked in the high-energy foods (mean change $=-0.398)$ than the low-energy foods $(-0.488)$, compared to the equivalent changes in the safe condition (high-energy: -0.077 ; low-energy: 0.018 ). It was also noted that the main effect of energy level was only significant in the social scenario $(F(1,179)=25.927, P<0.001$, partial eta squared $=0.127$ ) where, after reading the social environment scenarios, participants experienced a greater decrease in desire for low-energy (mean change $=-0.28$ ) than high-energy foods $(-0.051)$.

\section{Changes in desirability for main food categories}

Finally, we investigated effects of environmental harshness on changes in desirability for foods in the major food categories (vegetables, fruits, dairy, grains, sweets and meats). We therefore conducted a further repeated-measures ANOVA with food category as the within-subject factor and harshness as the between-group factor. This analysis (Fig. 4) revealed no significant food category $\times$ harshness interaction effects in either the social $(F(5,895)=1.36, P=0.251$, partial eta squared $=0.008)$ or economic $(F(5,975)=1.59$, $P=0.188$, partial eta squared $=0.008$ ) scenarios. However there was a significant interaction effect in the physical scenario $(F(5,920)=2.67, P=0.030$, partial eta squared $=$ 0.014 ), such that the generally large decrease in desirability scores in the harsh condition was much less marked for the category "sweets." Indeed, post-hoc analyses showed that while there was no significant difference between food categories in the safe scenario, in the harsh physical scenario the desire for sweets decreased significantly less (mean change $=-0.291)$ than the remaining food categories: vegetables $(-0.482 ; P=0.028)$, fruits $(-0.518 ; P=0.004)$, dairy $(-0.440 ; P=0.051)$, grains $(-0.465 ; P=0.022)$, meats $(-0.463 ; P=0.018)$.

In this analysis, we also found a significant main effect of food category for the social scenarios $(F(5,895)=18.90$, $P<0.001$, partial eta squared $=0.096)$ but not for either the economic $(F(5,975)=0.60, P=0.669$, partial eta squared $=$ $0.003)$ or physical safety $(F(5,920)=0.90, P=0.419$, partial eta squared $=0.005)$ scenarios. Fig. 4 suggests this is again largely driven by the increased desirability of sweets, while desirability of all other food categories decreased following the manipulation. Indeed post-hoc analysis showed an increase in 


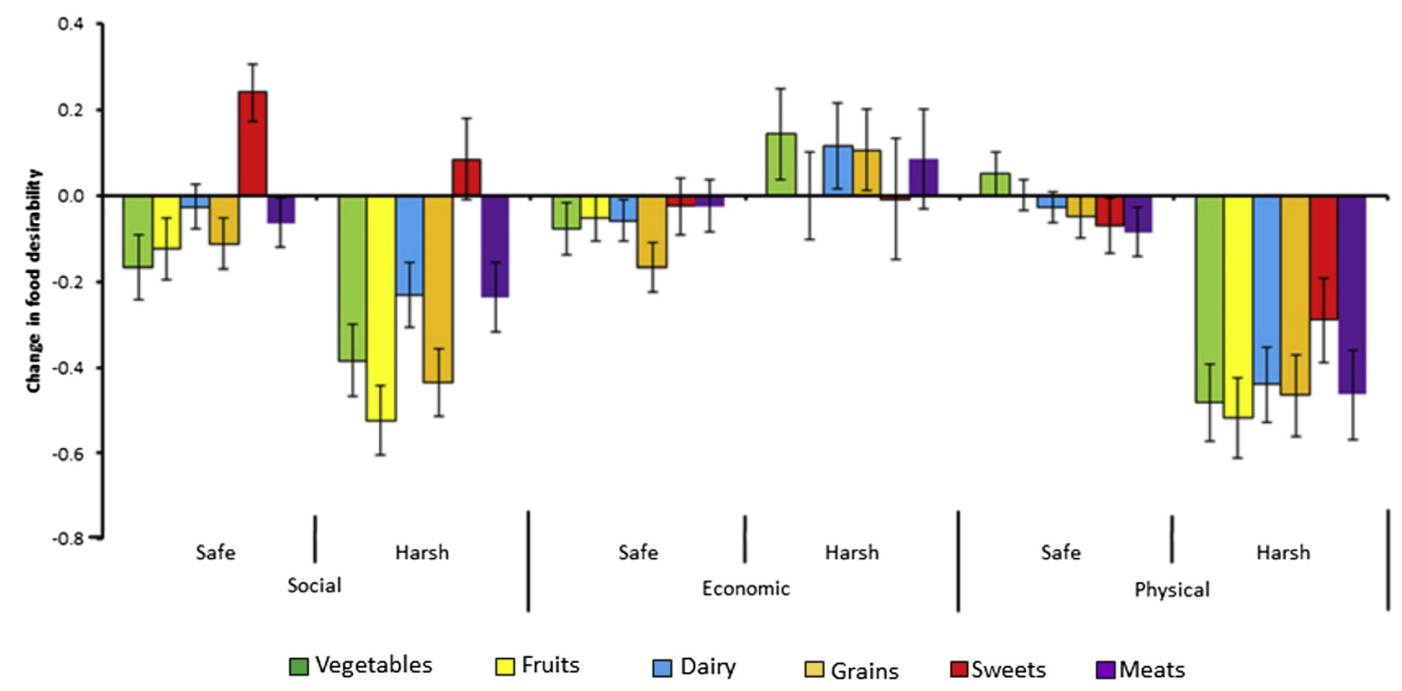

Fig. 4. Difference in mean pre-test and mean post-test food desirability scores by food category

desirability for sweets across the social scenario was significantly higher than for vegetables $(0.438)$, fruits $(0.486)$, dairy (0.291), grains $(0.435)$ and meats $(0.313$; all $P<0.001)$.

\section{DISCUSSION}

Previous research has demonstrated that the desire for food can be influenced by manipulating perceptions of environmental harshness (Laran \& Salerno, 2013). Swaffield and Roberts (2015) also showed that reading a simple text scenario that included dimensions of harsh social, economic and physical safety conditions could also increase the desire for high-energy dense foods. In light of this, the current study aimed to isolate and compare the effects of these three environmental dimensions on desirability of different kinds of food.

The results showed that exposure to cues of low social support and high physical threat reduce the desire to eat, whereas cues of economic harshness had little effect. Further analysis revealed a significant interaction between energy level of different foods and perceived threat to physical safety. In the first analysis a between-subjects comparison was performed. This analysis showed there was a small increase in appetite for all foods when exposed to the harsh economic scenario. Second, when an analysis was performed based on energy density, it was found that in the harsh and safe social scenarios there was a significant difference in desire for low- and high-energy dense foods. The significant finding was that when exposed to the harsh social scenario the desire for low-energy dense foods decreased significantly more than high-energy dense foods. Lastly, when individual food categories were analyzed, there was a consistent decrease in desire for all foods in the harsh physical scenario.

At first sight, the overall pattern of these results may appear to be at odds with the previous findings of Swaffield and Roberts (2015), which showed the desire for high- energy dense foods increased in response to perceived levels of environmental harshness. Whereas in the current study, there was more often a decrease in food desirability scores for both low- and high-energy dense foods. The reason for this discrepancy may be due to the use of different scenario manipulations that generated a higher level of stress. In the Swaffield and Roberts (2015) study, the safe and harsh scenarios were short (about 140 words). These original scenarios blended together the social, economic and physical safety dimensions into each story. In contrast, in this experiment each harshness dimension was isolated and presented as its own scenario. Each of these scenarios were also approximately three times longer (each about 440 words). It is possible that the longer scenario length and the adapted content may have been perceived to be harsher and thus, generated a higher level of stress. If the scenarios were perceived to be more stressful, this would likely have contributed to the general effect of reducing food desire. Apart from this difference, however, the results are not inconsistent with the previous study, as the reduction in desirability in the physical safety condition (the only scenario which generated a significant interaction between perceived harshness and calorific value) was less pronounced in high-energy foods; that is, they were more desirable under these conditions than low-energy foods. The same pattern is evident in the harsh social condition (Fig. 3), although the interaction was not significant.

Overall, the analyses showed that the three kinds of environmental harshness do have different effects on food desirability. First, perceived social isolation and threat to physical safety each reduced desirability, while economic harshness had little or no effect. Second, when the calorific value of the food items was taken into account, there was a differential effect on desirability only in the physical safety scenarios, such that the reduction in food desirability arising from threats to physical safety were stronger for low-energy foods than high-energy foods. Third, when foods were split into the six major food categories, the reduction in 
desirability under threat of physical safety was much less marked for the category "sweets" compared to vegetables, fruits, grains, dairy and meats.

Why do these different forms of perceived environmental harshness affect overall desire for foods, and affect it differently for different kinds of food? One reason may be related to the levels of stress induced by the different scenario manipulations. As previously mentioned, prior research has shown that low intensity stressors increase appetite (Born et al., 2009) whereas high intensity stressors decrease appetite (Sinha \& Jastreboff, 2013; Torres \& Nowson, 2007). If, as we might suppose, immediate threats to physical safety are more salient and present high levels of stress compared with threats to social connections and economic prospects, this would explain the differences observed in the results. At the same time, even if overall desire for foods is reduced under physical or social harshness, this appears to be less marked for high-energy foods, consistent with expectations about dietary preferences under relatively harsh environmental conditions.

Another notable finding from the third analysis is the special case of the food category "sweets". This was the only food category for which desirability increased for participants after reading the social scenarios, and the one that was substantially less affected compared to other food categories in the harsh physical safety scenario (see Fig. 4). Sweets rank among the foods offering highest calorific returns and are most easily digested (although it should be noted that while sweets usually contain high concentrations of sugar, they frequently contain fat too). These points are relevant for the interpretation of the effect in the physical safety scenario, but there may be a different explanation for the increase following the social scenarios. The safe social scenario was written in a manner that included a gathering of family and friends and was very much a celebration of friendship. These types of social gathering often involve sweets and other highenergy dense foods as they increase the hedonic value of the social gathering. In addition, when food is a part of a social gathering, it may contribute to bringing a group together and promote group bonding (Wittig et al., 2014). These associations may be responsible for the increased desire for sweets after reading the social scenarios, and perhaps are especially important under threat of social isolation.

\section{LIMITATIONS}

There are a number of potential limitations that should be considered when interpreting the results of this study. First, it is important to note that, while this study measured changes in food desire, it did not measure actual food intake. We cannot say with certainty that the scenarios will either increase or decrease the volume of foods consumed. Measuring actual food intake would be an important step for future research. However, these results, do demonstrate that different types of perceived environmental harshness influence appetite in different ways. These results have implications for our wider understanding of contextdependent eating behavior and how food preference may be adaptive under different environmental conditions.

Second, it should be acknowledged that although this study isolated and examined the effects of different types of environmental harshness on food choice, it would be rare to find an environment where only one type of harshness exists. There is a greater likelihood that all three conditions would co-exist in varying degrees. In addition, it is possible that variables associated with one environmental condition could affect the development of other conditions. For example, it is possible that a harsh economic environment could contribute to harsh physical safety conditions. Furthermore, it is possible that one type of harshness could generate a state of anxiety. This state of anxiety could affect how one perceives other types of environmental conditions.

The third factor that should be considered is the effect of one's early childhood environment. As previously noted, childhood sexual and physical abuse doubles one's likelihood of being overweight or obese as an adult (Rohde et al., 2008). Despite the fact the current study was based on a withinsubjects and between-subjects design, we cannot ignore the potential influence of childhood conditions on how an adult responds to stress, appetite and food preference.

Fourth, it would be prudent to acknowledge that there are socio-cultural differences that affect how people perceive and respond in psychological experiments. These differences may impact the generalizability of research findings across cultures. Henrich, Heine, and Norenzayan (2010) note that samples drawn entirely from Western, Educated, Industrialized, Rich, and Democratic (WEIRD) societies often respond differently on psychological tests than societies with an opposite profile. While it is unknown whether the results found in this study are affected by cultural variations, it should be noted that this is a potential limitation of this study.

The fifth consideration is related to the complexity of the construct of environmental harshness. In this study we examined the effect of three dimensions, social, economic and physical safety. While these dimensions are part of a harsh environment, they should not be considered exhaustive. It is likely that other dimensions of harshness do exist. These unknown dimensions could also have an effect on stress, appetite and food preference.

Lastly, in the Safe and Harsh Social scenarios different food items were mentioned. One might question whether mentioning food items may be a confounding variable that could affect the results in the social scenario posttests. The brief mention of these food items should be looked at in context. That is, they helped to generate a feeling of isolation and loneliness or a feeling of safety and social support. What is more, is that in the pre-test the participants had just looked at 30 full-color food pictures and evaluated the desirability of each item. Therefore, we infer that it is unlikely that these brief mentions of food would be a confounding variable that would affect the post-test results in the social scenarios. 
That being said, we cannot say for certain that these mentions had an effect or not.

\section{APPENDIX 1.}

\section{FULL-TEXT VERSIONS OF THE 6 SCENARIOS}

\section{Social Support: Safe condition*}

You walk down the carpeted hall and turn the doorknob, happy to find that it's not locked because your partner must be home. As you push open the door, savory spices waft from the kitchen-your partner must be cooking. Then suddenly you are gaping at a room full of beautiful smiling faces and greeted by a joyous shout: SURPRISE! And it really IS a surprise. Your jaw drops and you let out a breath as the blood rushes to your face. You feel your smile widening into a huge grin. And they're all there. You knew your partner was getting a lot of phone calls at home lately, but now you know why; they've been setting this up for weeks. Your mum and dad are there, each with an arm round your partner, who can't stop laughing, right there in the middle of everyone. Your two sweet sisters and your brother, who's wearing a little cone birthday party hat, blowing one of those wheezy stretch-whistles and making one of his usual goofy faces. The whole family has gathered from across three provinces to be here for your birthday, and you never had a clue. You suddenly notice your best friend from back home, who must have driven up here with your parents. A tear runs down your old friend's cheek, next to that gigantic smile you remember so well, and have missed so much lately, in spite of all your Facebook conversations. Your own eyes start to moisten and you bite your lip a little to keep the happy-tears back. Two of your closest friends are there from work, and three of your neighbors, including the sweet, hard-of-hearing old lady from down the hall who always brings you cookies. They all seem to have gotten to know one another before you even got here. It's like your family has not only suddenly appeared from out of the blue, but has expanded instantly to include your favorite people from here in the city.

You remember saying goodbye to some of these same folks a few years ago and coming to a city where you didn't know a soul and how lonely that was at first. That feeling has been gone for a long time now, and tonight you feel connected to everyone here, and connected to this city, your home now. And you feel surrounded by love.

Pause for a moment and think about the story you just read. How would you feel if this really was your situation?

\section{Social Support: Harsh condition*}

You trudge down the hallway, fish for your key, and your heart sinks. A few months ago that door would have been unlocked, and your partner would be waiting for you. Tonight as you push open the door the air is dead and all you can hear is the low buzzing of a fan. You drop your bag in the hall closet-it makes a thud as it hits the floor. It is quiet and you can hear your footsteps as you cross the kitchen tile. You swing open the fridge and a cold draft hits you. You pull out a small milk carton and set it on the table, then cross to the dishwasher, pull out a cup, set it on the table and fill it. You sit, take a big sip. The milk is cold and makes you shiver. Sadly, you pull yourself up and swing open the fridge again. There's a plastic container with half of yesterday's can of chicken soup in it. On the shelf below there's a foam take-out box with the remains of the beef and rice from the night before. You close the fridge door and sit back down.

Should you get take-out delivered again? Maybe pizza this time. For a special occasion. Some occasion! Why did you come to this city? You may not have liked everybody in your little town, but at least you had your family and a few good friends. And people knew one another, looked out for one another. Despite the fact that you have been in the city for a while now you haven't made one friend. And now your partner's gone, too: couldn't take it. Headed back to that little town. Or maybe couldn't take you. Guess you'll never know, since your ex won't speak to you or even email.

You pull out your phone and turn it on. No messages, not even from anyone in your family. You tug the fridge door open and pull out the beef and rice, pop it in the microwave, and stand waiting for the ping. The microwave signals it's done and you grab the food and a fork from the dishwasher, then cross into the main room. You drop yourself onto the empty love seat and punch the remote. Canned laughter bleats from the TV. It's a rerun of an old sitcom about a group of friends. You take a bite of beef and your stomach knots. Tears fill your eyes. It's your birthday. And you've never felt so lonely.

Pause for a moment and think about the story you just read. How would you feel if this really was your situation?

\section{Economic prospects: Safe condition}

You turn into the parking lot and park your new car, careful not to scratch it on the post. There's a spring in your step as you cross the lot and step through the sliding doors into your bank. You walk up to the Loans and Mortgage desk and pull the original papers out of your bag. The lady behind the desk looks puzzled, but she smiles at you and her eyes sparkle through her glasses.

"Can I help you?" she asks. You realize you're grinning as you pass the mortgage papers to her. "I want to finish paying this off, please" "Oh, well, that's nice. All in one payment?"

"That's correct", you say. She smiles back at you. "Let me pull up your file." She taps away at her keyboard and studies the file for a moment. "Yes, you can do that without penalty under these terms. Did you want me to transfer it from your account?" You grin even harder and nod.

It's taken many years to get to this point, but it's still nowhere near as long as you had once expected. Now everything is happening quickly. It's not as if you haven't worked hard for it, and you'll keep working hard. Well, that's assuming you'll keep working. Maybe you could retire early? 
You've slowly worked your way up in the company, and you've been responsible and diligent. You're known as a good worker, and your job is secure. Financially you've always been fairly comfortable, and had enough for a bit more than the basics. But you've sometimes had to be careful with your money. Restaurants not too often, mostly short vacation trips, and you've driven the same car for quite a few years until yesterday.

But thanks to poor Uncle Bill, that's all changed. Last month the inheritance money from your great uncle came through to your account. It's enough to buy a new car, pay down the remaining fifteen years on the home mortgage and still have enough to add to the company pension and saving a good chunk of cash for the future. The money situation has been pretty good in recent years, but now, with the mortgage taken care of, you'll own your own home. As the mortgage and loans lady stamps "Paid" across your mortgage papers, you feel fully financially secure and at ease.

Pause for a moment and think about the story you just read. How would you feel if this really was your situation?

\section{Economic prospects: Harsh condition}

You step off the bus and begin the one block walk to your bank that's located in the middle of an old strip mall. As you get close to the mall you walk slowly across a dusty parking lot, rehearsing once again what you'll say. You notice for the first time that the sole on your shoe is splitting off. Maybe you can glue it when you get home. You hope the bank people don't notice. You think to yourself, "How did you ever get into this situation?" You've never been rich, but now you're hitting bottom.

It started when the company went out of businesswithout any warning. No severance, nobody to sign the employment statement that EI-Employment Insurance Canada-wanted. After weeks of filling out forms and going from one stubborn bureaucrat to another, you finally you got them to accept the pay stubs and the news article about the company's demise as proof. You looked for work but the downturn has made jobs really scarce. Then unemployment insurance ran out and the car was repossessed. And now this.

Your heart beats rapidly as you walk into the bank. You get into the lineup for tellers, and stand there for a few minutes, sweaty hands in your pockets, shuffling along behind some guy in a suit, whose new shoes shine under the fluorescent lights. Your stomach grumbles and you think about one more lunch of Kraft dinner. You then notice there's a different counter that says "Loans and Mortgages". You feel a bit foolish for not noticing it sooner. You cross over and look towards the lady standing behind the counter, but you can't look her in the eye. You reach into your bag and pull out the mortgage papers and the threatening letters you've been getting from the bank for several months. You look at the lady smiling innocently at you. At least this isn't the angry one you had to talk with last month, who kept you waiting for an hour and sneered at you when she had to give you a one-month extension. Your stomach cramps. You're already four months overdue. Why would they give you yet another extension? They'll own the house completely in two days, and you'll be on the street. This time, it feels hopeless. You're not going to make it out of this hole. You really don't know what you're going to do.

Pause for a moment and think about the story that you just read. How would you feel if this really was your situation?

\section{Physical Safety: Safe condition}

As you amble along the elm-lined street, a white-haired man raking golden leaves on his lawn smiles and waves. You smile and wave back, then look up at the way the late afternoon sun makes the elm leaves glow above you. You love taking your time on the way home from work-it's a pleasant and relaxing walk and most people here are friendly or at least look completely harmless. Some of them remember you from your childhood or at least know your family. There's hardly any traffic, and the few cars you see are going very slowly. Recently, you managed to get a job transfer back to your home town which made you happy. You don't miss the city at all.

In the city, you used to have to walk through the worst section of town at least twice a day. You looked around constantly to ensure you were safe. But all that's been behind you now. Today you are feeling safe and breathing a lot easier.

The wonderful thing about this town is the way everyone keeps an eye out for you. Not that the local police are not good at what they do. It's just that they don't have that much to do. Bob, the local cop, seems to spend most of his time at the downtown coffee shop, because there's rarely much need for his services. That's why you feel a bit silly as you come up to your house and pull out your new set of keys. The keys were brought to your office today by the local locksmith. You guess you must have brought your old city mentality with you when you asked him to change the locks and install a new deadbolt on your front door.

The new door handle and locks sparkle brightly in the afternoon sun. You open the lock for the first time. The key slips in snugly and easily. You unlock the handle lock, then the dead bolt, then walk through the door. As you close it behind you and hear a comforting click as the door closes securely behind you. You feel completely, utterly safe.

Pause for a moment and think about the story you just read. How would you feel if this really was your situation?

\section{Harsh Environment: Physical Safety}

It's after midnight and you are on the last bus of the night. You reach up and pull the cord to signal your stop-the bell rings. You ride this bus in daylight every day but haven't had to come home so late before. You stand, the brakes squeal and you are thrown forward as the bus pulls up to your stop. You're hesitant to get off, but you'll have a lot further to walk if you don't move quickly. As you step onto the hard pavement you pause, thinking once again about the body that was found in the alley behind the bus stop last month. 
The bus hisses and clanks, pulling away in a fog of diesel fumes. You ask yourself, "what got into your head a few years ago when you left the safety of your little town for this dark and dangerous city?"

You take a deep breath and peer into the dark alleynothing but darkness. You survey the rust-riddled parked cars along the road. Hopefully, no one is lurking behind them. Then you see a guy sitting behind the wheel across the street, his face shadowed. A dog barks and snarls somewhere nearby. You move quickly along the sidewalk, past a row of pawn shops and cash stores, their smudged windows shuttered with steel grating.

You hear the rumble of a big car behind you. It drifts slowly along. It feels like it is following you. You glance back quickly. It's the car with the shadowy-faced driver you saw on the other side of the street. You see his face this time-a sharp face, smiling weirdly, watching you. You pick up your pace and are breathing hard as you cover the last block. He's still there, the car crawling along beside you like a wolf following you at the edge of a forest. You turn off on your side street and he drifts by.

The lights along this street are out for some reason. It's dark but you're breathing a little easier to see that the car has missed the turn and drifted on past. Then, as you make the corner, you see light swing across the apartments on your left. You look behind and see headlights approaching. They blind you at first. Then, as the car creeps closer and slows down, you see it's the same car. As it gets closer to you, your heart races and your whole body tightens like a vice.

Pause for a moment and think about the story you just read. How would you feel if this really was your situation?

\section{REFERENCES}

Alvarez, J., Pavao, J., Baumrind, N., \& Kimerling, R. (2007). The relationship between child abuse and adult obesity among California women. American Journal Preventative Medicine, 33(1), 28-33. https://doi.org/10.1016/j.amepre.2007.02.036.

Baker, R. (2005). Recommended effect size statistics for repeated measures designs. Behavior Research Methods, 37(3), 379-384. https://doi.org/10.3758/BF03192707.

Bauer, K., Hearst, M., Escoto, K., Berge, J., \& Neumark-Sztainer, D. (2012). Parental employment and work family stress: Associations with family food environments. Social Science \& Medicine, 75, 496-504. https://doi.org/10.1016/j.socscimed.2012.03.026.

Baumeister, R., \& Leary, M. (1995). The need to belong: Desire for interpersonal attachments as a fundamental human motivation. Psychological Bulletin, 117(3), 497-529.

Blanca, M. J., Alarcon, R., Arnau, J., Bono, R., \& Bendayan, R. (2017). Non-normal data: Is ANOVA still a valid option?. Psicothema, 29(4), 552-557. https://doi.org/10.7334/psicothema2016.383.

Borders, T., Rohrer, J., \& Cardarelli, K. (2006). Gender-specific disparities in obesity. Journal of Community Health, 31(1), 57-67. https://doi.org/10.1007/s10900-005-8189-8.

Born, J., Lemmens, S., Rutters, F., Nieuwenhuizen, A., Formisano, E., Goebel, R., et al. (2009). Acute stress and food-related reward activation in the brain during food choice during eating in the absence of hunger. International Journal of Obesity, 34, 172-181. https://doi.org/10.1038/ijo.2009.221.

British Nutrition Foundation (2009). Retrieved from http://www. nutrition.org.uk/healthyliving/fuller/what-is-energy-density. html.

Crittenden, A. N., \& Zes, D. A. (2015). Food sharing among Hadza Hunter-Gatherer children. PLoS One, 10(7), e0131996. https:// doi.org/10.1371/journal.pone.0131996.

Cunliffe, V. T. (2016). The epigenetic impacts of social stress: How does social adversity become biologically embedded? Epigenomics, 8(12), 1653-1669. https://doi.org/10.2217/epi2016-0075.

Dagher, A. (2009). The neurobiology of appetite: Hunger as addiction. International Journal of Obesity, 33, S30-S33.

Dressler, H., \& Smith, C. (2013). Food choice, eating behavior, and food liking differs between lean/normal and overweight/obese, low-income women. Appetite, 65, 145-152. https://doi.org/10. 1016/j.appet.2013.01.013.

Drewnowski, A., \& Specter, S. E. (2004). Poverty and obesity: The role of energy density and energy costs. American Society for Clinical Nutrition, 79, 6-16.

Enloe, J. G. (2003). Food sharing past and present. Before Farming, 2003(1), 1-23. https://doi.org/10.3828/bfarm.2003.1.1.

Garawi, F., Devries, K., Thorogood, N., \& Uauy, R. (2014). Global differences between women and men in the prevalence of obesity: Is there an association with gender inequality? European Journal of Clinical Nutrition, 68(10), 1101-1106. https://doi.org/10.1038/ejen.2014.86.

Gardner, K. R., Sapienza, C., \& Fisher, J. O. (2015). Genetic and epigenetic associations to obesity- related appetite phenotypes among African-American children. Pediatric Obesity, 10(6), 476-482. https://doi.org/10.1111/ijpo.12010.

Gunstad, J., Paul, R., Spitznagel, M., Cohen, R., Williams, L., Kohn, M., et al. (2006). Exposure to early life trauma is associated with adult obesity. Psychiatric Research, 142(1), 31-37. https://doi. org/10.1016/j.psychres.2005.11.007.

Hadjichrysanthou, C., \& Broom, M. (2012). When should animals share food? Game theory applied to kleptoparasitic populations with food sharing. Behavioral Ecology, 23(5), 977-991. https:// doi.org/10.1093/beheco/ars061.

Heijmans, B. T., Tobi, E. W., Stein, A. D., Putter, H., Blauw, G. J., Susser, E. S., et al. (2008). Persistent epigenetic differences associated with prenatal exposure to famine in humans. Proceedings of the National Academy of Sciences, 105(44), 1704617049. https://doi.org/10.1073/pnas.0806560105.

Hill, S., Griskevicius, V., Prokosch, M., \& Kramer, A. (2016). Low childhood socioeconomic status promotes eating in the absence of energy need. Psychological Science, 27(3), 354-364. https:// doi.org/10.1177/0956797615621901.

Henrich, J., Heine, S. J., \& Norenzayan, A. (2010). The weirdest people in the world?. Behavioral and Brain Sciences, 33(2-3), 175. https://doi.org/10.2139/ssrn.1601785.

Hill, S. E., Rodeheffer, C. D., Delpriore, D. J., \& Butterfield, M. E. (2013). Ecological contingencies in women's calorie regulation psychology: A life history approach. Journal of Experimental Social Psychology, 49(5), 888-897. https://doi.org/10.1016/j.jesp. 2013.03.016. 
Imam, M. U., \& Ismail, M. (2017). The impact of traditional food and lifestyle behavior on epigenetic burden of chronic disease. Global Challenges, 1(8), 1700043. https://doi.org/10.1002/gch2. 201700043.

Kaplan, H., Hill, K., Lancaster, J., \& Hurtado, M. (2000). A theory of human life history evolution: Diet, intelligence, and longevity. Evolutionary Anthropology: Issues, News, and Reviews, 9(4), 156-185. https://doi.org/10.1002/1520-6505.

Kruger, D. J., \& Kruger, J. S. (2016). Psychometric assessment of human life history predicts health related behaviors. Pychological Topics, 25(1), 19-28.

Laran, J., \& Salerno, A. (2013). Life-history strategy, food choice, and caloric consumption. Psychological Science, 24, 167-173. https://doi.org/10.1177/0956797612450033.

Latzer, Y., Hochdorf, Z., Bachar, E., \& Canetti, L. (2002). Attachment style and family functioning as discriminating factors in eating disorders. Contemporary Family Therapy, 24(4), 581-599.

Li, C., \& Lumey, L. H. (2019). Interaction or mediation by adult obesity of the relation between fetal famine exposure and type 2 diabetes?. International Journal of Epidemiology, 48(2), 654656. https://doi.org/10.1093/ije/dyy293.

MacFarlane, A., Crawford, D., Ball, K., Savige, G., \& Worsely, A. (2007). Adolescent home food environments and socioeconomic position. Asia Pacific Journal of Clinical Nutrition, 16(4), 748-756. https://doi.org/10.6133/apjcn.2007.16.4.23.

Macleod, J., Smith, G. D., Metcalfe, C., \& Hart, C. (2005). Is subjective social status a more important determinant of health than objective social status? Evidence from a prospective observational study of Scottishmen. Social Science \& Medicine, 61, 1916-1929. https://doi.org/10.1016/j.socscimed.2005.04.009.

Mccullough, M. E., Pedersen, E. J., Schroder, J. M., Tabak, B. A., \& Carver, C. S. (2013). Harsh childhood environmental characteristics predict exploitation and retaliation in humans. Proceedings of the Royal Society B: Biological Sciences, 280(1750), 20122104. https://doi.org/10.1098/rspb.2012.2104.

Mcgregor, J. A., \& Pouw, N. (2016). Towards an economics of wellbeing. Cambridge Journal of Economics, 41(4), 1123-1142. https://doi.org/10.1093/cje/bew044.

McLaren, L. (2007). Socioeconomic status and obesity. Epidemiologic Reviews, 29(1), 29-48. https://doi.org/10.1093/epirev/ mxm001.

Meng, R., Lv, J., Yu, C., Guo, Y., Bian, Z., Yang, L., et al. (2018). Prenatal famine exposure, adult obesity patterns and risk of type 2 diabetes. International Journal of Epidemiology, 47, 399408. https://doi.org/10.1093/ije/dyx228.

Mittal, C., \& Griskevicius, V. (2014). Sense of control under uncertainty depends on people's childhood environment: A life history theory approach. Journal of Personality and Social Psychology, 107(4), 621-637. https://doi.org/10.1037/a0037398.

Nettle, D., Andrews, C., \& Bateson, M. (2016). Food insecurity as a driver of obesity in humans: The insurance hypothesis. Behavioral and Brain Sciences, 1-34. https://doi.org/10.1017/ s0140525x16000947.

Nettle, D., Joly, M., Broadbent, E., Smith, C., Tittle, E., \& Bateson, M. (2019). Opportunistic food consumption in relation to childhood and adult food insecurity: An exploratory correlational study. Appetite, 132, 222-229. https://doi.org/10.1016/j. appet.2018.07.018.
O'Shaughnessy, R., \& Dallos, R. (2009). Attachment research and eating disorders: A review of the literature. Clinical Child Psychology and Psychiatry, 14(4), 559-574. https://doi.org/10.1177/ 1359104509339082.

Pott, W., Albayrak, O., Hebebrand, J., \& Pauli-Pott, U. (2009). Treating childhood obesity: Family background variables in a weight-control intervention. International Journal of Eating Disorders, 42(3), 284-289. https://doi.org/10.1002/eat.20655.

Robertson, F., Coall, D., Mcaullay, D., \& Nannup, A. (2019). Intergenerational influences of hunger and community violence on the aboriginal people of Western Australia: A review. International Journal of Critical Indigenous Studies, 12(2), 34-46. https://doi.org/10.5204/ijcis.v12i1.1183.

Rohde, P., Ichikawa, L., Simon, G., Ludman, E., Linde, J., Jeffery, R., et al. (2007). Associations of child sexual and physical abuse and depression in middle-aged women. Child Abuse \& Neglect, 32, 878-887. https://doi.org/10.1016/j.chiabu.2007.11.004.

Sapolsky, R. M. (2004). Why zebras don't get ulcers: The acclaimed guide to stress, stress related diseases, and coping, pp. 1-18. New York: W.H. Freeman.

Schoe, M., Iongh, H. H. D., \& Croes, B. M. (2009). Humans displacing lions and stealing their food in Bénoué National Park, North Cameroon. African Journal of Ecology, 47(3), 445-447. https://doi.org/10.1111/j.1365-2028.2008.00975.x.

Shaw, R., Green, M., Popham, F., \& Benzeval, M. (2014). Differences in adiposity trajectories by birth cohort and childhood social class: Evidence from cohorts born in the 1930s, 1950s and 1970s in the west of Scotland. Journal of Epidemiology \& Community Health, 68(6), 550-556. https://doi.org/10.1136/jech-2013-203551.

Sinha, R., \& Jastreboff, A. M. (2013). Stress as a common risk factor for obesity and addiction. Biological Psychiatry, 73, 827-835. https://doi.org/10.1016/j.biopsych.2013.01.032.

Stevens, J. R. (2004). The selfish nature of generosity: Harassment and food sharing in primates. Proceedings of the Royal Society of London. Series B: Biological Sciences, 271(1538), 451-456. https://doi.org/10.1098/rspb.2003.2625.

Stojek, M., Fischer, S., \& MacKillop, J. (2015). Stress, cues, and eating behavior. Using drug addiction paradigms to understand motivation for food. Appetite, 92, 252-260. https://doi.org/10. 1016/j.appet.2015.05.027.

Swaffield, J., \& Roberts, S. C. (2015). Exposure to cues of harsh or safe environmental conditions alters food preferences. Evolutionary Psychological Science, 1, 69-76. https://doi.org/10.1007/ s40806-014-0007-z.

Tate, E., Spruit-Metz, D., Pickering, T., \& Pentz, M. (2015) Two facets of stress and indirect effects on child diet through emotion-driven eating. Eating Behaviors, 18, 84-90. https://doi. org/10.1016/j.eatbeh.2015.04.006.

Torres, S., \& Nowson, C. (2007). Relationship between stress, eating behavior, and obesity. Nutrition, 23, 887-894. https://doi.org/ 10.1016/j.nut.2007.08.008.

Troisi, J., \& Gabriel, G. (2011). Chicken soup really is good for the soul: Comfort food fulfils the need to belong. Psychological Science, 22(6), 747-753. https://doi.org/10.1177/0956797611407931.

Ty, M., \& Francis, A. (2013). Insecure attachment and disordered eating in women: The mediating process of social comparison and emotional dysregulation. Eating Disorders, 21, 154-174. https://doi.org/10.1080/10640266.2013.761089. 
United States Department of Labor. (2018). Unemployment rates and earnings by educational attainment. (2018, March 27). Retrieved from https://www.bls.gov/emp/chart-unemploymentearnings-education.htm.

Wells, J. C. K. (2010). The evolutionary biology of human fatness. Cambridge: Cambridge University Press. https://www.cambridge. org/9780521884204.

Williamson, D., Thompson, T., Anda, R., Dietz, W., \& Felitti, V. (2002). Body weight and obesity in adults and self-reported abuse in childhood. International Journal of Obesity, 26, 1075-1082.

Wittig, R., Crockford, C., Deschner, T., Langergraber, K., Ziegler, T., \& Zuberbuhler, K. (2014). Food sharing is linked to urinary oxytocin levels and bonding in related and unrelated wild chimpanzees. Proceedings of the Royal Society B: Biological Sciences, 281(1778), 20133096-20133096. https://doi.org/10. 1098/rspb.2013.3096.

World Health Organization. (2018). Obesity and Overweight. Retrieved from December 24, 2018. https://www.who.int/newsroom/fact-sheets/detail/obesity-and-overweight.

Zhou, J., Zhang, L., Xuan, P., Fan, Y., Yang, L., Hu, C., et al. (2018). The relationship between famine exposure during early life and body mass index in adulthood: A systematic review and metaanalysis. PLoS One, 13(2), e0192212. https://doi.org/10.1371/ journal.pone.0192212. 